\title{
PHYSICAL FITNESS OF WOMEN FROM BIAŁA PODLASKA AGED 60 OR OLDER
}

\author{
DAMIAN JABŁOŃSKI
}

\author{
Józef Pitsudski University of Physical Education in Warsaw, Faculty of Physical Education and Health in Biata \\ Podlaska, Department of Sport for All
}

\author{
Mailing address: Damian Jabłoński, Józef Piłsudski University of Physical Education in Warsaw, Department of Sport \\ for All, 2 Akademicka Street; 21-500 Biała Podlaska, e-mail: damian.jablonski@awf-bp.edu.pl
}

\begin{abstract}
Introduction. The ongoing process of aging in the Polish society generates the necessity to take interest in the problems and needs of the elderly population. Age-appropriate fitness is an important factor contributing to an optimal level of seniors' life quality and maintaining their independence in everyday life. The aim of this research was to evaluate the level of physical fitness of elderly women from Biała Podlaska with respect to their age and body build. Material and Methods. The research included 38 women attending activities in culture centers in Biała Podlaska. Measurements of basic somatic parameters were used to evaluate their body build on the basis of BMI. The Fullerton Test was applied to determine the level of physical fitness. Results. In all trials of the Fullerton tests, most of the seniors achieved normal or above normal results. Statistically significant correlations were found between BMI and the test results in most trials. Correlations between age and test results were observed only in the endurance test. Conclusions. The female respondents present a high level of physical fitness in relation to American standards. Due to the high percentage of respondents with excessive body weight, there is a need to develop relevant physical activity programs for this age group of women.
\end{abstract}

Key words: physical fitness, seniors, women, body build, Fullerton Test

\section{Introduction}

The process of involution, which can be observed as we age, has many negative effects on the organism of every person. The risk of osteoporosis, inadequate water balance and problems with concentration or loss of muscle strength are just a few factors that contribute to a significant deterioration of physical fitness of the body, which affects the quality of life in the older age $[1,2,3]$.

Among factors that determine healthy aging, motor skills, mainly functional ones, have a very strong impact on the level of tangible quality of life. The decrease in functionality results in the dependence on other people or the environment. Consequently, fulfillment of such needs is strongly limited. The ability to maintain satisfactory fitness manifested by good health condition and general mobility is very important for elderly people $[4,5,6,7,8]$.

Nowadays, people are living longer and, at the same time, they are striving to maintain the highest possible quality of life and independence. The continuing process of demographic aging of population has resulted in an increased focus on the problems and needs of older people. The research carried out in this area indicates not only the needs, but also the possibilities of undertaking activities that slow down the involution processes and prevent aggravation of existing disabilities. According to many authors, enhancing physical activity is one of the most important and effective ways to prevent and eliminate health problems in older age. World Health Organization emphasizes the role of physical activity especially in present times, when people have been exposed to a sedentary lifestyle $[9,10,11]$. Expected independence requires sufficient strength to get out of bed or a chair, get in and out of a car, move around the neighborhood, shop, and climb stairs. The level of agility and flexibility should be high enough to put on shoes, get dressed, or fasten seat belts in a car. Finally, an adequate level of coordination and balance minimizes the risk of falls, which are the biggest danger for seniors. Seniors can be active in daily life, go for walks or enjoy other forms of recreation provided their level of endurance is sufficient [12].

The aim of this research was to evaluate the level of physical fitness of women from Biała Podlaska aged 60 or older with regard to their age and body build. Prior to the study, the following research questions and hypotheses were formulated:

1. Which components of physical fitness of the respondents were at an acceptable level and which differed from the standards developed for the American population?

2. Is there a difference in the level of physical fitness among women depending on their body mass index?

3. Is there a difference in the level of physical fitness between different age groups?

4. Are there any relationships between the particular variables?

It was assumed that:

- The level of the female respondents' functional abilities would reach normative values.

- Individuals with excessive body weight would perform worse than individuals with normal body build.

- The results of individual fitness tests of the older respondents would be worse than those of the younger seniors.

- There would be correlations between results of fitness tests and age of respondents as well as BMI values.

\section{Material and Methods}

The study conducted in February 2020 included 38 women aged 60-74 (average age of the group: 66.84 \pm 4.26 ) attending activities in culture centers in Biała Podlaska. Three age groups were discriminated for comparative purposes (Fig. 1).

Measurements of basic somatic features: body height (measured with the accuracy of $0.1 \mathrm{~cm}$ ) and body weight (measured with the accuracy of $0.1 \mathrm{~kg}$ ) were used in the evaluation of 


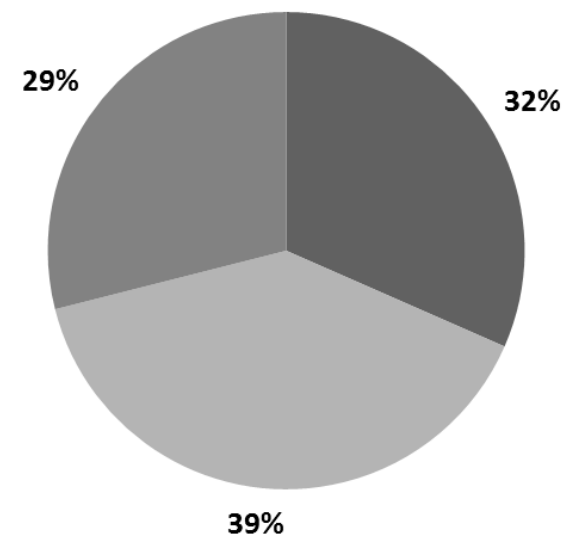

-60-64 y.o. $\quad 65-69$ y.o. $\quad$ 70-74 y.o.

Figure 1. Percentage breakdown of each age group (y.o. - years old)

body build. The measurements were used to calculate the body mass index (BMI) and to evaluate body build. Based on these results, three groups of women were identified: with normal body build (BMI 18.5-24.9), overweight (BMI 25.0-29.9) and obese $(\mathrm{BMI}>29.9)$ [13].

Physical fitness of the women was evaluated by the application of the Fullerton Functional Fitness Test, which is designed for people over 60 and is used to evaluate motor skills necessary to maintain independence and safe daily activities, such as endurance, flexibility, strength, agility, and dynamic balance. The test is completely safe for both very active and inactive seniors and consists of six motor trials. All trials were conducted according to the instructions of the test authors (Rikli \& Jones) and the results were related to the indicated norms, appropriately adjusting the measurement units (inches, pounds) to the Polish conditions, which were developed by Różańska-Kirschke with co-authors $[14,15,16]$.

The material was organized and processed using the computer program STATISTICA. The Shapiro-Wilk test was used to analyze the data, which showed their normal and near normal distribution. Arithmetic means, medians, and standard deviations were calculated. The non-parametric Kruskal-Wallis rank ANOVA test and the one-way ANOVA analysis of variance with Tukey's test were conducted to compare the results according to age and body build, in which women divided by age and BMI level were taken as grouping factors, while fitness tests were taken as a dependent factor. Test probabilities at $\mathrm{p} \leq 0.05$ were considered significant. Correlations between variables were examined using the Spearman's non-parametric test and Kendall's tau test.

The research was approved by the Senate Committee on Research Ethics of Józef Piłsudski University of Physical Education in Warsaw (SKE 01-05/2021). Its participants were healthy individuals who were informed about the purpose and course of the research, as well as about the possibility of withdrawal at any time during the test. Exercises could be discontinued if the respondents felt unwell, experienced shortness of breath, dizziness, or any pain, or if they did not have the strength to continue. The performance of the various elements of the trial for each participant was preceded by its demonstration and making sure that the respondent understood what the test consisted of.

\section{Results}

The respondents were characterized by a significant variation in somatic parameters, which was reflected in the BMI values. The largest group was composed of persons with excessive body mass, so were overweight and obesity present at a similar frequency (Tab. 1, Fig. 2).

Table 1. Descriptive statistics of body build indices

\begin{tabular}{|c|c|c|c|}
\hline & $\mathrm{x} \pm \mathrm{SD}$ & $\mathrm{R}$ & $\mathrm{Me}$ \\
\hline Height $[\mathrm{cm}]$ & $159.6 \pm 4.6$ & $151.0-168.0$ & 160.0 \\
\hline Weight $[\mathrm{kg}]$ & $70.75 \pm 12.71$ & $47.4-112.0$ & 71.25 \\
\hline BMI & $27.67 \pm 4.15$ & $19.23-40.16$ & 27.49 \\
\hline
\end{tabular}

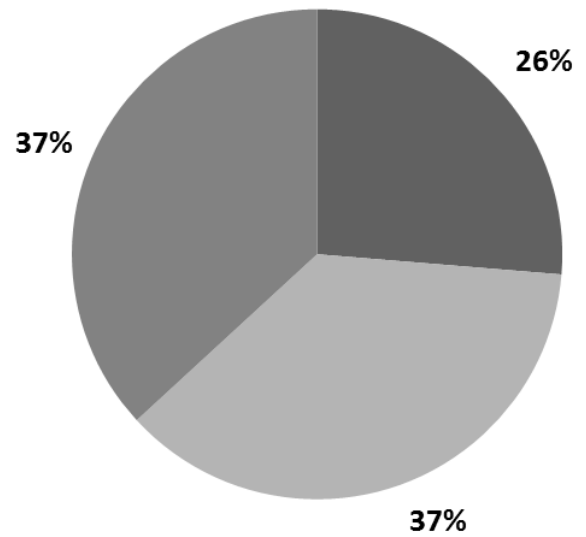

normal weight overweight a obesity

Figure 2. Percentage breakdown of BMI level of respondents

The average results of particular trials obtained in the Fullerton Test are presented in Tables 2 and 3.

The analysis of variance showed statistically significant differences between the results of the oldest and the youngest women in the 2 -minute step test $(p=0.005)$, while in the back scratch trial such a difference was demonstrated between 65-69-year-olds and women aged 70-74 ( $\mathrm{p}=0.025)$, to the disadvantage of the oldest group. Statistically significant differences were also observed between the results of respondents considering their BMI. Obese respondents were significantly weaker than normal-weight seniors in the chair stand $(\mathrm{p}=0.02)$ and '8-foot up-and-go' ( $\mathrm{p}=0.033$ ) trials. In other trials, the differences between the groups were present, but not statistically significant (Tab. 2 and 3).

On the basis of the correlation analyses it was shown that there are statistically significant relationships between the respondents' BMI and the results of the following trials: chair stand, arm curl, back scratch and ' 8 foot up-and-go'. Participants with lower BMI performed better than those with higher BMI. The positive correlation with the ' 8 foot up-and-go' trial indicates that the higher the BMI was, the more time it took respondents to complete the test. The correlation between the results and age was observed only in the 2-minute step test (tau-Kendall $=-0.43)$. It turned out that the older the person was, the lower the test result was. The age factor did not significantly affect the results in other trials (Tab. 4). 
Table 2. Average values of the Fullerton test results with regard to the age of women

\begin{tabular}{|c|c|c|c|c|}
\hline \multirow{2}{*}{ Trial } & \multirow{2}{*}{$\begin{array}{c}\text { Total } \\
\mathrm{x} \pm \text { SD }\end{array}$} & $\begin{array}{c}60-64 \\
(\mathrm{n}=12)\end{array}$ & $\begin{array}{c}65-69 \\
(\mathrm{n}=15)\end{array}$ & $\begin{array}{c}70-74 \\
(\mathrm{n}=11)\end{array}$ \\
\cline { 3 - 5 } & & 16.8 & 18.3 & 16.2 \\
\hline Chair Stand (rep.) & $17.21 \pm 5.11$ & 21.6 & 19.9 & 20.1 \\
\hline Arm Curl (rep.) & $20.47 \pm 5.01$ & 111.5 & 102.6 & 85.9 \\
\hline 2-Min Step Test (rep.) & $100.61 \pm 20.28$ & 11 & 4.4 & 1.7 \\
\hline Chair Sit-and-Reach (cm) & $2.26 \pm 5.42$ & 0.1 & -0.8 & -10.6 \\
\hline Back Scratch (cm) & $-4.71 \pm 9.57$ & -4.3 & -3.9 \\
\hline 8 Foot Up-and-Go (s) & $5.62 \pm 0.98$ & 5.43 & 5.37 & 6.15 \\
\hline
\end{tabular}

Table 3. Trial average values of the Fullerton Test with regard to female body build

\begin{tabular}{|c|c|c|c|c|}
\hline \multirow{2}{*}{ Trial } & \multirow{2}{*}{$\begin{array}{c}\text { Total } \\
\mathrm{x} \pm \mathrm{SD}\end{array}$} & $\begin{array}{c}\text { Normal } \\
\text { weight } \\
(\mathrm{n}=10)\end{array}$ & $\begin{array}{c}\text { Over- } \\
\text { weight } \\
(\mathrm{n}=14)\end{array}$ & $\begin{array}{c}\text { Obesity } \\
(\mathrm{n}=14)\end{array}$ \\
\cline { 3 - 5 } & & 19.7 & 18.4 & 14.2 \\
\hline Chair Stand (rep.) & $17.21 \pm 5.11$ & 21.0 & 22.4 & 18.2 \\
\hline Arm Curl (rep.) & $20.47 \pm 5.01$ & 102.4 & 104.7 & 95.2 \\
\hline 2-Min Step Test (rep.) & $100.61 \pm 20.28$ & 10.4 & 1.9 \\
\hline Chair Sit-and-Reach (cm) & $2.26 \pm 5.42$ & 3.0 & 2.1 & -7.6 \\
\hline Back Scratch (cm) & $-4.71 \pm 9.57$ & -0.3 & -4.9 & 6.09 \\
\hline 8 Foot Up-and-Go (s) & $5.62 \pm 0.98$ & 5.09 & 5.52 & 6.09 \\
\hline
\end{tabular}

Table 4. Correlations between particular trial results of the Fullerton Test vs. BMI and the age of seniors

\begin{tabular}{|c|c|c|}
\hline Trial (Estimated Parameter) & Age & BMI \\
\hline Chair Stand (lower body strength) & -0.09 & $-0.41^{*}$ \\
\hline Arm Curl (upper body strength) & -0.15 & $-0.26^{*}$ \\
\hline 2-Min Step Test (aerobic endurance) & $-0.43^{*}$ & -0.16 \\
\hline Chair Sit-and-Reach (lower body flexibility) & 0.10 & -0.10 \\
\hline Back Scratch (upper body flexibility) & -0.10 & $-0.31^{*}$ \\
\hline 8 Foot Up-and-Go (agility/dynamic balance) & 0.22 & $0.35^{*}$ \\
\hline
\end{tabular}

* - statistically significant difference $\mathrm{p}<0.05$.
In the analysis of correlations between particular trials, the results of the flexibility trials (the chair sit-and-reach) were found to correlate significantly. There was also a correlation between the back scratch trial and the 2-minute step test, but it was not significant. All other trials correlated with each other, with the exception to the flexibility trials (Tab. 5).

The vast majority of the women in each of the trials performed within or above the standards set out by the Fullerton Test authors. The best results were observed among the seniors in trials assessing upper and lower limb strength (most results above the standard) and endurance. The highest number of participants who did not meet the standard was observed in trials assessing upper body flexibility (21\%) and agility and dynamic balance (18\%) (Fig. 3).

When dividing the respondents into age groups, worse results in the Fullerton Test were observed among the oldest people; however, when comparing their results to age-specific standards, we noticed that this group achieved the highest number of results above the standard in trials assessing upper and lower body strength, while strength, agility and upper body flexibility tests were within the standard among the vast majority of respondents. The most unfavourable situation was observed in the back scratch trial (upper body flexibility), where

Table 5. Correlations between particular trial results of the Fullerton Test in the senior women of Biała Podlaska

\begin{tabular}{|c|c|c|c|c|c|c|}
\hline Trial & $\begin{array}{c}\text { Chair } \\
\text { Stand }\end{array}$ & $\begin{array}{c}\text { Arm } \\
\text { Curl }\end{array}$ & $\begin{array}{c}\text { 2-Min } \\
\text { Step Test }\end{array}$ & $\begin{array}{c}\text { Chair Sit- } \\
\text { and-Reach }\end{array}$ & $\begin{array}{c}\text { Back } \\
\text { Scratch }\end{array}$ & $\begin{array}{c}\text { 8 Foot Up- } \\
\text { and-Go }\end{array}$ \\
\hline $\begin{array}{c}\text { Chair } \\
\text { Stand }\end{array}$ & & & & & & \\
\hline $\begin{array}{c}\text { Arm } \\
\text { Curl }\end{array}$ & $0.488^{*}$ & & & & & \\
\hline $\begin{array}{c}\text { 2-Min } \\
\text { Step Test }\end{array}$ & $0.312^{*}$ & $0.248^{*}$ & & & & \\
\hline $\begin{array}{c}\text { Chair Sit- } \\
\text { and-Reach }\end{array}$ & 0.168 & 0.115 & 0.131 & & & \\
\hline $\begin{array}{c}\text { Back } \\
\text { Scratch }\end{array}$ & 0.146 & 0.094 & $0.239^{*}$ & $0.321^{*}$ & & \\
\hline $\begin{array}{c}\text { 8 Foot Up- } \\
\text { and-Go }\end{array}$ & $-0.416^{*}$ & $-0.345^{*}$ & $-0.443^{*}$ & -0.140 & -0.195 & \\
\hline
\end{tabular}

* - statistically significant difference $\mathrm{p}<0.05$.

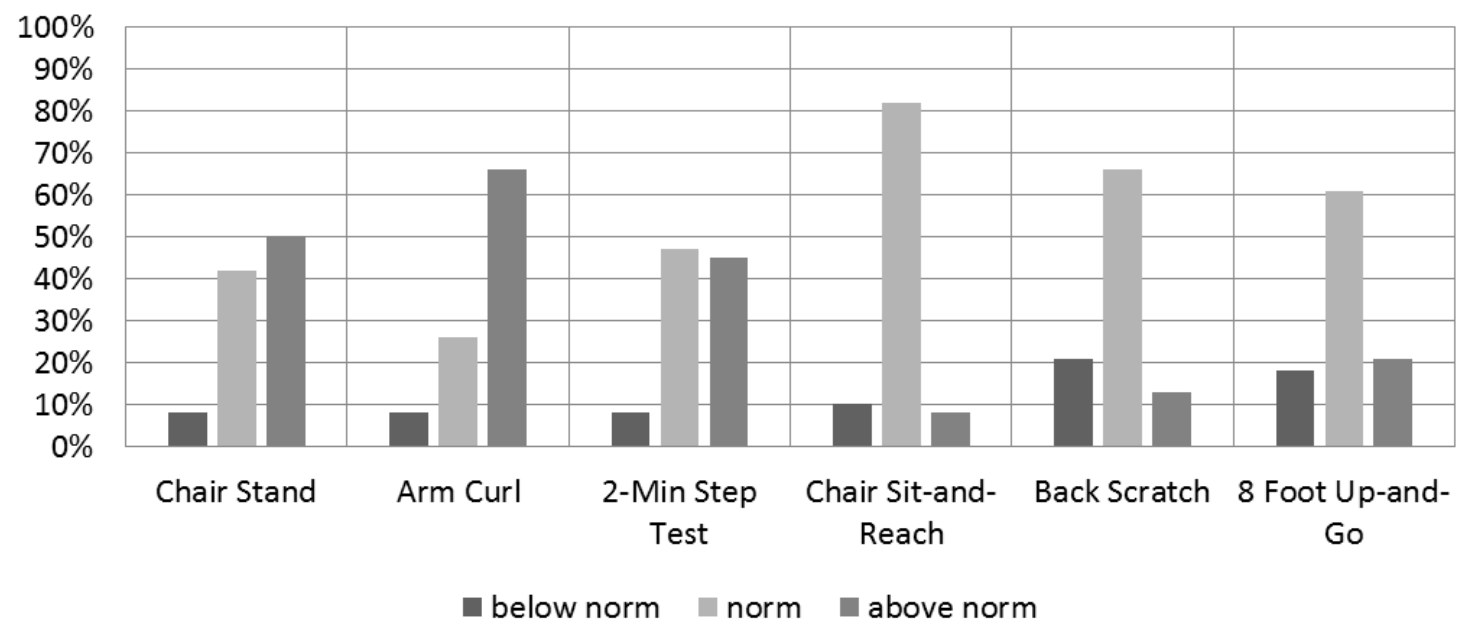

Figure 3. Percentage breakdown of women's results compared to standards set out by the authors of the Fullerton Functional Fitness Test 
almost half of the women aged 70-74 achieved results below the standard. Among seniors aged 60-64 and 65-69, the arm curl trial, the 2-minute step test, and the chair stand trial, which indirectly assessed upper and lower limb strength and endurance, showed the best results compared to standards. The vast majority of results in each age group met or even exceeded the upper limit of US standards (Tab. 6).

Taking into account the BMI level, it can be noticed that the participants with normal body weight are by far the best, obtaining almost all results within or above the standards developed for the American population. Only two results out of the entire Fullerton Test were below the standard - in the flexibility

Table 6. Percentage breakdown of women qualifying for the standards set out by the authors of the Fullerton Functional Fitness Test with regard to age

\begin{tabular}{|c|c|c|c|c|c|c|c|c|c|}
\hline \multirow{2}{*}{ Age } & \multicolumn{3}{|c|}{$\begin{array}{c}60-64 \\
(\mathrm{n}=12)\end{array}$} & \multicolumn{3}{c|}{$\begin{array}{c}65-69 \\
(\mathrm{n}=15)\end{array}$} & \multicolumn{3}{c|}{$\begin{array}{c}70-74 \\
(\mathrm{n}=11)\end{array}$} \\
\cline { 2 - 9 } Trial & $\downarrow$ & $\mathrm{n}$. & $\uparrow$ & $\downarrow$ & $\mathrm{n}$. & $\uparrow$ & $\downarrow$ & $\mathrm{n}$. & $\uparrow$ \\
\hline $\begin{array}{c}\text { Chair } \\
\text { Stand }\end{array}$ & $17 \%$ & $33 \%$ & $50 \%$ & $0 \%$ & $53 \%$ & $47 \%$ & $0 \%$ & $45 \%$ & $55 \%$ \\
\hline $\begin{array}{c}\text { Arm } \\
\text { Curl }\end{array}$ & $8 \%$ & $17 \%$ & $75 \%$ & $7 \%$ & $33 \%$ & $60 \%$ & $9 \%$ & $27 \%$ & $64 \%$ \\
\hline $\begin{array}{c}2-\text {-Min } \\
\text { Step Test }\end{array}$ & $0 \%$ & $33 \%$ & $67 \%$ & $13 \%$ & $33 \%$ & $54 \%$ & $9 \%$ & $82 \%$ & $9 \%$ \\
\hline $\begin{array}{c}\text { Chair } \\
\text { Sit-and- } \\
\text { Reach }\end{array}$ & $17 \%$ & $83 \%$ & $0 \%$ & $7 \%$ & $80 \%$ & $13 \%$ & $9 \%$ & $82 \%$ & $9 \%$ \\
\hline $\begin{array}{c}\text { Back } \\
\text { Scratch }\end{array}$ & $17 \%$ & $83 \%$ & $0 \%$ & $13 \%$ & $54 \%$ & $33 \%$ & $45 \%$ & $55 \%$ & $0 \%$ \\
\hline $\begin{array}{c}8 \text { Foot } \\
\text { Up-and- } \\
\text { Go }\end{array}$ & $25 \%$ & $67 \%$ & $8 \%$ & $13 \%$ & $47 \%$ & $40 \%$ & $18 \%$ & $73 \%$ & $9 \%$ \\
\hline
\end{tabular}

$\downarrow$ - below-norm; n. - norm; $\uparrow$ - above-norm.

Table 7. Percentage breakdown of women qualifying for the standards set out by the authors of the Fullerton Functional Fitness Test with regard to BMI

\begin{tabular}{|c|c|c|c|c|c|c|c|c|c|}
\hline \multirow{2}{*}{ Age } & \multicolumn{3}{|c|}{$\begin{array}{c}\text { Normal weight } \\
(\mathrm{n}=10)\end{array}$} & \multicolumn{3}{c|}{$\begin{array}{c}\text { Overweight } \\
(\mathrm{n}=14)\end{array}$} & \multicolumn{3}{c|}{$\begin{array}{c}\text { Obesity } \\
(\mathrm{n}=14)\end{array}$} \\
\cline { 2 - 9 } Trial & $\downarrow$ & $\mathrm{n}$. & $\uparrow$ & $\downarrow$ & $\mathrm{n}$. & $\uparrow$ & $\downarrow$ & $\mathrm{n}$. & $\uparrow$ \\
\hline $\begin{array}{c}\text { Chair } \\
\text { Stand }\end{array}$ & $0 \%$ & $30 \%$ & $70 \%$ & $14 \%$ & $7 \%$ & $79 \%$ & $7 \%$ & $86 \%$ & $7 \%$ \\
\hline $\begin{array}{c}\text { Arm } \\
\text { Curl }\end{array}$ & $0 \%$ & $20 \%$ & $80 \%$ & $7 \%$ & $14 \%$ & $79 \%$ & $0 \%$ & $57 \%$ & $43 \%$ \\
\hline $\begin{array}{c}\text { 2-Min } \\
\text { Step Test }\end{array}$ & $0 \%$ & $70 \%$ & $30 \%$ & $7 \%$ & $36 \%$ & $57 \%$ & $14 \%$ & $43 \%$ & $43 \%$ \\
\hline $\begin{array}{c}\text { Chair } \\
\text { Sit-and- } \\
\text { Reach }\end{array}$ & $10 \%$ & $70 \%$ & $10 \%$ & $7 \%$ & $86 \%$ & $7 \%$ & $14 \%$ & $79 \%$ & $7 \%$ \\
\hline $\begin{array}{c}\text { Back } \\
\text { Scratch }\end{array}$ & $10 \%$ & $60 \%$ & $30 \%$ & $21 \%$ & $72 \%$ & $7 \%$ & $29 \%$ & $64 \%$ & $7 \%$ \\
\hline $\begin{array}{c}8 \text { Foot } \\
\text { Up-and- } \\
\text { Go }\end{array}$ & $0 \%$ & $70 \%$ & $30 \%$ & $21 \%$ & $58 \%$ & $21 \%$ & $29 \%$ & $57 \%$ & $14 \%$ \\
\hline
\end{tabular}

$\downarrow$ - below-norm; n. - norm; $\uparrow$ - above-norm. tests. The chair stand and arm curl trials (upper and lower limb strength tests) were performed the best in this group, with $70 \%$ and $90 \%$ of the participants obtaining results above the standard. Slightly worse results were observed in the group with the highest BMI, but most of them were still within normal limits (Tab. 7).

\section{Discussion}

When analysing the available demographic data, it is possible to notice a constantly emerging process of population aging. According to demographic forecasts by the Central Statistical Office, by 2050 the number of children and adults is expected to decrease significantly, while the number of elderly people (over 65) will increase significantly. By the end of this period, in rural areas, the share of elderly people will exceed 30\% (an increase by $16,8 \%$ ) and in the cities it will be even $35 \%$ (an increase by $19 \%)$ [17].

It is extremely important to take care of seniors' health, as the proper level of their functional fitness helps them to cope with the difficulties of everyday life effectively. Furthermore, physical fitness is recognised as one of the basic elements of good health, so it is a paramount value. That is why an important role is attributed to the development of motor skills and morphological-structural predispositions [18, 19, 20].

The FFFT - Fullerton Functional Fitness Test, developed by the American researchers Rikli and Jones, is a tool which comprehensively evaluates physical fitness of seniors.

Based on this test, the analysis of physical fitness of Polish residents over 65 was carried out by Zieliński [21]. The research was conducted on a group of 1017 women. Four following trials were used as a measure: chair stand, chair sit-and-reach, 8-foot up-and-go and 2-minute step test. In all presented types of physical fitness trials, the results of the Polish group were worse than those of the American participants. The most unfavourable differences were observed in agility and endurance tests.

The evaluation of the level of physical fitness of men and women over 60 residing in Poznan in comparison to the physical fitness of the population in the USA was also conducted by Król-Zielińska and co-authors [22]. The findings showed that in the category of women aged 60-69, the results of tests assessing the strength of upper and lower limb muscles were similar in both Polish and American women. The analysis of lower body flexibility showed that Polish women in this category achieved slightly weaker results, and the test assessing agility and dynamic balance presented much worse results than in the American population.

A similar evaluation of functional fitness based on the Fullerton Test was also carried out by Grześkowiak, Wieliński and Ignasiak [23, 24]. The results of the Fullerton test and the relevant analyses conducted by Grześkowiak and Wieliński who examined the level of physical fitness of female residents of a social welfare home for elderly people in Poznan showed, with the exception to the lower body flexibility test, that the results were significantly worse than those of a comparative group tested in the USA. These results, however, were not surprising as they may have resulted from the fact that such social welfare homes house people whose health condition did not allow them to function independently.

The findings of Ignasiak's study on the level of physical fitness in elderly women based on the Fullerton Test, which were unfavourable for the Polish population, confirm those of Grześkowiak and Zieliński's research. In her study, Ignasiak showed that the research conducted in the USA presented bet- 
ter results in five trials of the Fullerton test than the values obtained in women of both social welfare homes and sanatoriums. It was concluded that the American standards are too rigorous and that reference values should be developed for the Polish population [24].

The findings presented in this study do not confirm the above conclusions. Namely, female residents of social welfare homes for elderly people and patients of sanatoriums performed significantly worse in particular trials. For the residents of social welfare homes and seniors in sanatoriums the range of standards turned out to be too high in most trials. This may be explained by the fact that they were not very active, sometimes even not very independent, and had a low level of awareness of the impact of physical activity on their health. On the contrary, the women from Biała Podlaska presented a completely different attitude.

Comparing the test results to the standards set out for the elderly population in the USA, it can be concluded that the standards turned out to be not too high. In the presented study, the women achieved very good results in all the trials of the test, which lets us conclude that this group is composed of people characterised by fair physical fitness. The vast majority of the seniors managed to fit within or above the normal range in each trial. Most of the respondents were members of culture centres, which may indicate that they were active in life and not afraid of taking up new challenges. Therefore, it should not be surprising that they obtained such good results in the Fullerton Test. Thus, it may be concluded that the respondents were characterised by appropriate physical fitness which they should continue to maintain at this level, and take care to improve those fitness parameters which may have deviated slightly from the standards. The least favourable results were obtained in trials assessing agility and dynamic balance as well as upper body flexibility due to the highest percentage of respondents not qualifying for the standard. Nevertheless, there were very few of such individuals. The best results, compared to the applied standards, were observed in the arm curl trial (indirectly assessing upper limb strength) and the chair stand trial and the 2-minute step test (assessing lower limb strength and endurance). Similar results were presented by Zdrodowska. Her findings show that in all trials female respondents obtained positive results after normalization to the average result of the American population. The most significant differences in comparison to the standards were also observed in the arm curl trial [25]. As the author observed, it seemed that the result may have been influenced by the modification of the applied test due to the original weight units. In this test, the women bent their forearms with a weight of $2 \mathrm{~kg}$ (because such weights are available on the Polish market), while the American women had a weight of $2.27 \mathrm{~kg}$. The difference in load probably contributed to the differences in the results.

Favourable for the Polish population results were obtained by Prystupa [26]. Comparing the arithmetic means of all trials by women from the University of the Third Age at the Academy of Physical Education to the standards for the American population, it was found that the standards turned out to be appropriate. The senior women fell within the range of the proper physical fitness standard in every trial. It was similar among the women from the Academy of the Third Age Arts, who performed satisfactorily in most of the trials. Only the test assessing aerobic endurance proved too difficult and did not allow the seniors to meet the standard.

In Rutkowska's research, the results of each individual tested in four out of six trials were also within normal and above normal limits. However, almost half of respondents obtained results below normal in both upper and lower body flexibility tests [27].

The BMI factor should also be taken into account in a multidimensional evaluation of physical fitness parameters as it is important in risk assessment of diseases and problems associated with overweight and obesity [1]. The issue of the relationship between BMI and physical fitness has been addressed by many researchers. It is well known that in cases of excessive fatness, fitness deteriorates. In the present study, the arithmetic means of the BMI weight and height index in the study group are characteristic of overweight individuals.

The observed index results are similar to those presented by other authors $[24,25,28]$. In contrast to Zdrodowska's findings [25], which only showed a relationship between BMI and upper body flexibility, this research indicates a significant interdependence between this index and majority of particular fitness trials. The study by Prystupa et al. [26] and Szczygielska-Babiuch et al. [29] also demonstrated a strong correlation between BMI and physical fitness among female respondents. It can be assumed that excessive body weight of female seniors significantly affected the results obtained in these trials. Respondents with very high BMI classified as obese, had worse results than those with lower BMI, but still the majority of respondents fell within the standards developed for the American population. The situation was similar when the respondents were divided into age groups. The respondents representing the oldest age group obtained worse results than the younger age group, but in relation to the standards for their age almost all respondents showed very good results - within the standards or better. It is noteworthy that the average results of the senior women aged 65 69 in the following trials: chair stand, chair sit-and-reach, back scratch and 8-foot up-and-go were slightly better than those of their younger counterparts from the group of 60-64-year-olds. Although the differences in test results between these groups were not statistically significant, they were observable.

Unfortunately, the research shows that the majority of elderly people in Poland are characterised by low levels of activity and fitness, especially those aged $70+$. At the beginning of the 21 st century, up to $80 \%$ of Polish seniors did not see any indication or need for rehabilitation $[13,30]$ and their lifestyle was described as passive [4]. In 2008 almost $3 / 4$ of the population over 60 was physically inactive. However, the present study and the results of recent research may provide evidence that year after year health awareness of elderly people regarding physical activity and their functional fitness is increasing.

Nevertheless, due to the large proportion of overweight respondents, it would be appropriate to broaden the research focus to overweight and obese individuals and to develop appropriate physical activity programs to reduce the height-weight index in these individuals.

It was also noted that sometimes researchers encounter problems in interpreting the results in some tests, related to the original units of measurement, not always taking into account that the standards are given, for example, in inches and not centimeters. The development of standards for the Fullerton Test in Polish conditions will contribute to its more effective use in our country and a more reliable evaluation of the health and fitness level in the Polish senior population, as it has been pointed out by most researchers using this tool.

\section{Conclusions}

1) The group of women from Biała Podlaska who were evaluated by the Fullerton Test was characterised by a very high lev- 
el of physical fitness in comparison to the American standards. The majority of senior women achieved results within or above the standards. The best results were obtained in tests assessing upper and lower body strength and endurance.

2) There were statistically significant differences in the Fullerton Test results between normal and obese participants in the chair stand trial, which indirectly assesses lower limb muscle strength, and in the 8-foot up-and-go trial, which assesses agility and dynamic balance.

3) Statistically significant differences were found in relation to age in the 2-minute step test and the back scratch trial assessing endurance and upper body flexibility, to the disadvantage of the oldest respondents.

4) Significant correlations were found between the respondents' BMI and four out of six Fullerton Test trials, as well as between the age of the seniors and the 2-minute step trial. Additionally, correlations between the results of particular fitness parameters were observed.

\section{References}

1. Osiński W. (2002). Physical activity undertaken by elderly people. Antropomotoryka 24, 3-24. [in Polish]

2. Duda K. (2012). The aging process. In: A. Marchewka, Z. Dąbrowski, J.A. Żołądź (eds), Aging physiology. Prevention and rehabilitation (pp. 1-31). Warszawa: Wydawnictwo Naukowe PWN. [in Polish]

3. Budzińska K. (2005). The influence of organism aging on skeletal muscle biology. Gerontologia Polska 13(1), 1-7. [in Polish]

4. Kozdroń E. (2014). Recreational activity in the process of successful aging. Zeszyty Naukowe Wyższa Szkoła Kultury Fizycznej i Turystyki 9, 75-84. [in Polish]

5. Doherty TJ (2003). Invited review: Aging and sarcopenia. Journal of Applied Physiology 95(4), 1717-1727.

6. Kaczmarczyk M., Trafiałek E. (2007). Activating the elderly as a chance for successful aging. Gerontologia Polska 15, 116118. [in Polish]

7. Sas-Nowosielski K., Hadzik A., Górna J., Grabara M. (2016). Applying the health belief model in explaining the stages of exercise change in older adults. Polish Journal of Sport and Tourism 23(4), 221-225. DOI: 10.1515/pjst-2016-0029

8. Razaghi S., Saemi E., Abedanzadeh R. (2020). The effect of external attentional focus and self-controlled feedback on motor learning in older adults. Polish Journal of Sport and Tourism 27(1), 9-13. DOI: 10.2478/pjst-2020-0002

9. Hagerman F.C., Walsh S.J., Staron R.S., Hikida R.S., Gilders R.M. et al. (2000). Effects of high-intensity resistance training on untrained older men. I. Strength, cardiovascular, and metabolic responses. The Journals of Gerontology, Series A: Biological Sciences and Medical Sciences 55(7), 336346.

10. Makuła W. (2010). Physical culture of aging generations in the light of research by selected Polish and foreign authors. Antropomotoryka 52, 119-130. [in Polish]

11. World Health Organization (2020). WHO guidelines on physical activity and sedentary behaviour. Geneva: World Health Organization.

12. Umiastowska D., Kupczyk J. (2020). Factors Differentiating the Level of Functional Fitness in Polish Seniors. International Journal of Environmental Research and Public Health 17(5), 1699.

13. Drozdowski Z. (2002). Anthropology for teachers of physical education. Poznań: AWF. [in Polish]
14. Jones C.J., Rikli R.E. (2002). Measuring functional fitness of older adults. The Journal on Active Aging 1(2), 25-30.

15. Rikli R.E., Jones C.J. (1999). Development and validation of Functional Fitness Test for Community-residing Older Adults. Journal of Aging and Physical Activity 7, 129-161.

16. Różańska-Kirschke A., Kocur P., Wilk M., Dylewicz P. (2006). Fullerton Test as a measure of physical fitness in the elderly. Rehabilitacja Medyczna 10(2), 15-19. [in Polish]

17. Główny Urząd Statystyczny (2014). Demographic situation of the elderly and the consequences of the aging of the Polish population in the light of the forecast for 2014-2050. Warszawa. [in Polish]

18. Ignasiak Z., Sławińska T. (2001). Physical fitness as a positive measure of health. Materials of the 10th Scientific Conference: Environmental determinants of children's health. Legnica. [in Polish]

19. Malina R.M., Bouchard C., Bar-Or O. (2004). Growth, maturation, and physical activity. Champaign IL: Human Kinetics.

20. Kozdroń E., Leś A. (2010). Motor activity in the process of successful aging. Postępy Rehabilitacji XXIV(I), 49-57. [in Polish]

21. Zieliński W. (2005). Physical fitness of the Polish and American populations after 64 years of age. Annales Universitates Maria Curie-Sklodowska, Medycyna 60(16), 432-435. [in Polish]

22. Król-Zielińska M., Osiński W., Zieliński J., Kusy K. (2006). Physical fitness of elderly people in Poland compared to the population of the United States. Studies in Physical Culture and Tourism 13, 53-55. [in Polish]

23. Grześkowiak J., Wieliński D. (2009). Comparison of selected parameters of physical fitness of women over 65, tested by the Fullerton Functional Fitness Test method with population studies conducted in the USA by Rikli and Jones. Antropomotoryka 19(45), 77-82. [in Polish]

24. Ignasiak Z., Kaczorowska A., Katan A., Domaradzki J. (2009). Physical fitness of older women as assessed by the Fullerton test. Fizjoterapia 17(2), 48-52. [in Polish]

25. Zdrodowska A., Wiszomirska I., Niemierzycka A., Czajkowska A., Magiera A., Słoń M. (2012). Physical fitness of women over 60 participating in the classes of the University of the Third Age. Postępy Rehabilitacji 33(3), 19-25. [in Polish]

26. Prystupa T., Bolach E., Bolach B., Migasiewicz J., Paliga Z. (2012). Assessment of physical fitness of women over 60 years of age. Pedagogy of Physical Culture and Sports 5, 137147. [in Polish]

27. Rutkowksa I., Marszałek J., Piotrowska J., Morgulec-Adamowicz N., Skowroński W. et al. (2011). Assessment of the functional fitness of students of the University of the Third Age of AWF in Warsaw. Postępy Rehabilitacji 25(4), 27-33. [in Polish]

28. Rogowski Ł., Szarek K., Dąbrowska G., Dziubek W. (2014). Assessment of the physical fitness of a group of seniors using the Fullerton test. Gerontologia Wspótczesna 4, 167173. [in Polish]

29. Szczygielska-Babiuch A., Lipińska-Stańczak M., Skrzypek M., Smakowska K., Stopa A. et al. (2019). The problem of overweight and physical fitness of women with osteoporosis - a pilot study. Gerontologia Polska 27, 27-35. [in Polish]

30. Osinski W. (2003). Anthropomotorics. Poznań: AWF. [in Polish]

Submitted: March 19, 2021

Accepted: June 28, 2021 